\title{
Intensity, Manifestation, and Performance in the Politics of the Real
}

\section{Hyun Kang Kim}

Faculty of Design, Peter Behrens School of Arts, University of Applied Sciences, Düsseldorf, Germany

\author{
Email address: \\ h.kim $a$ hs-duesseldorf.de
}

To cite this article:

Hyun Kang Kim. Intensity, Manifestation, and Performance in the Politics of the Real. International Journal of Philosophy. Vol. 7, No. 1, 2019, pp. 24-30. doi: 10.11648/j.ijp.20190701.14

Received: September 25, 2018; Accepted: November 20, 2018; Published: February 13, 2019

\begin{abstract}
This study attempts to explain the concept of the real in terms of intensity, manifestation, and performance, and then outlines key aspects of the politics of the real. The politics of the real is based on an interruption of identification and an abrupt end of continuity, and intensity, manifestation, and performance are the modalities of the politics of the real. First, intensity is the principle of punctualization. It denotes an anti-dialectic and anti-systematic enterprise that aims to leave behind the paradigm of continuity. It acts as the counter-principle to overcome the Hegelian dialectic and historicism. It concerns the dimension before the formation of identity and thus functions as a categorical rejection of ontological identity. Consequently, it evolves into a figure of future politics, because it denies identity and instead affirms new inventions. Second, manifestation is a matter of politics, because politics shows itself as a matter of visibility and demonstration. Ultimately, politics is the fight over manifestation. Furthermore, manifestation is the modality of existence of the collective, since a new arising collective always manifests itself in the space of images. Finally, performance is an action concept and thus opposed to the static world-model. Hence, the world appears as the place for restructuring and reshaping. Performance renders reference and the classical notion of mimesis obsolete. It undermines the distinction between original and copy and instead affirms the permanent generating of new relations and nexuses. Hence, it is the generation of freedom. Ultimately, it acts as a disappearing intermediary between virtual intensity and actual manifestation. It is an anti-metaphysical concept of possibility that differs strictly from metaphysical possibility. Thus, intensity, manifestation, and performance each correspond to the virtual, actual, and possible of the real and thus are to be denoted as modalities of the politics of the real.
\end{abstract}

Keywords: The Real, Intensity, Manifestation, Performance

\section{Introduction}

This study attempts to explain the concept of the politics of the real in terms of intensity, manifestation, and performance. To begin, one has to distinguish the politics of the real from Realpolitik. Whereas Realpolitik is accompanied by state, administration, hierarchy, identification, etc., the politics of the real is based on the interruption of identification. Realpolitik is therefore politics in the conservative sense, whereas the politics of the real is politics in the progressive sense. Since the politics of the real advocates for the abrupt end of continuity, it is associated with Benjamin's concept of the end of history as well as with Lacan's concept of the end of analysis.

The former contains the spectrum from the messianic to the Marxist concept, i.e., from the "transitoriness (Vergängnis)" [1] of the messianic nature and the messianic "now time" to the active "grip [...] on the emergency brake" [2] of the train of history. The latter is considered to be the constitutive element of Lacan's psychoanalysis whose operation consists in retroactively constructing the truth of a story from the end of the analysis. For both, the truth doesn't lie in the beginning of history but rather takes place at its end and sets itself retroactively as ground. This retroactivity of truth is in the center of the politics of the real, which appears as the unity of intensity, manifestation, and performance: The performance of the act lets the empty place of intensity transition into manifestation. 


\section{Intensity}

The initial question of the theory of the real is: Is there any place for meaning and subjectivity beyond an arbitrary setting? Is there any place for the real as truth? This question leads to the notion of a transcendental, which manifests as intensity. [3] Intensity is the point or the principle of punctualization. It denotes an anti-dialectic and an antisystematic enterprise that aims to leave behind the paradigm of a line, i.e., of continuity, linear development, and dialectical coming-to-itself. In other words, intensity acts as the counter-principle to overcome the Hegelian dialectic and historicism.

What is the "point"? [4] It is the incommensurable dimension of the factual, which always eludes generalization, universalization, and symbolization. The point disturbs the system that will never be able to capture it. It is the archenemy of system, structure, and identity. It is neither significant nor referential, but intense. It is the zero meaning as the difference in itself that generates all meaning. It is the embodiment of the absence of meaning. In other words, its presence corresponds to the absence of meaning, insofar as it marks the place of the lack itself instead of the missing meaning. Therefore, the theoretical consequence of the point is that the origin of meaning disappears, because it is generated in the process of signification itself, insofar as the point functions simultaneously as the point of zero meaning and as the source of meaning itself.

Intensity is the "structural neuter" that overrides system, structure, and paradigm. Roland Barthes calls the "field of non-paradigmatic intensities" the "neuter." "The intensity has to do with the neuter because it eludes the paradigm." [5] The relationship between intensity and paradigm can be summed up with the words of Barthes: "What's in the paradigm is outside the intensity." [6] Intensity is the always newly recurring life, which always provides new connections and constellations. It is the event: the unforeseen and immemorial.

The point of intensity is the counterpart to a system. The goal of the theory of intensity is to undermine a system, to identify gaps in it, and to build holes into it. Intensity undermines the discourse of domination and makes it vulnerable to criticism. It transforms the completed into the incomplete, and the incomplete into the complete: It is a messianic category, a category of destruction and completion. Significantly, Benjamin uses in the Theological-Political Fragment (1921) the notion of the "messianic intensity." [7]

In addition, the point of intensity is the counterpart of knowledge. For if there are only singular points, there is no universality of knowledge. Thus, since there is thus no coherent, systematic knowledge, one must start over with thinking each point. Thus, the point correlates with thinking that is opposed to knowledge, since knowledge is always the knowledge of the thinkable. Thinking, however, is the event of that which has yet to be thought. It is a mode of takingplace, whereas knowledge is always a mode of having-takenplace. If in the event of thinking the immemorial coincides with its pure appearance directly, i.e., if the unthinkable truth becomes its appearance itself, it is the very moment of truth.

Truth that has yet to be subjectified, i.e., manifested, doesn't do this step by step or in different stages. This is the account found in Hegel, who thinks of dialectics as process and development. The subjectification of that truth, in contrast, takes place in the manner of a leap. It happens suddenly in the modus of manifestation. Meanwhile, for Benjamin, dialectics is where thinking suddenly stops and the dialectic image arises. The instant (Augenblick) is the only modus of time in which time itself appears, because eternity is not mere duration or an endless dilatation of time. If that were true it would be nothing else but a quantification of time. Instead, eternity is the radical outside of quantitative time. It is the qualitative time par excellence, though it can't be considered as the opposition to quantitative time. Rather, it is the moment of maximum intensity. Therefore, eternity coincides directly with the instant that Benjamin called the "messianic intensity."

The instant is the time that "the blink of an eye needs," [8] the minimum time it takes to process what one has seen and has perceived. In short, it is the time for reflection. Since ancient Greece, it is the equivalent of transcendence. In modern times, however, it is no longer about the moment as transcendence, but about "moments with decreasing representation" or "vanishing transparency." [9] Hence, one has to distinguish between the moment with a claim of eternity, which has a long tradition in the history of philosophy up to German idealism, and the moment without duration as a punctualisation of time, which appears in romanticism and is predominant up to the modern time. The early Romantic period has been dominated notably by the eschatological temporality and the "feeling of the actual second." Remarkably, Carl Schmitt points out the distance towards systems and the tendency to "insubstantial dotting" in the early Romantic period. The punctualisation represents a necessary alternative to a system of thinking. [10]

The moment as eternity stands for the idealistic unity of subject and object, mind and nature. The moment as point, on the other hand, is the modus of appearance in which transcendence and intensity collide. Thus, it is the defense against transcendence. This starts already in the works of Kierkegaard. In his philosophy, the insistence of intensity is the only possible mental stance against transcendence. For Kierkegaard, transcendence changes into the transcendental as passionate liminal experience. The vanished transcendence is replaced by the intense experience of immanence, whereby this experience has to be paradoxically understood as "transcendence without transcendence." [11]

The moment as a point without duration is in itself meaningless and without reference. But it is precisely the moment from which everything else gains its meaning. The point is the immanent intensity. It is the "nonsense" [12] that, according to Deleuze, precedes and enables sense, although the point itself stays meaningless.

Thinking the point of intensity is accompanied by an antidialectical and anti-systematic account, which leads back to 
Kierkegaard's struggle with Hegel. Kierkegaard turns a particular point, which comprehends everything else, into an instance of the transcendental, namely into "decision." [13]

For Kierkegaard, the decision is elevated to the level of absolute instance; unlike in Hegel, who sets mediation (Vermittlung) as the instance of absolute knowledge. [14] Kierkegaard marks the beginning of the performative turn in philosophy when he states: "In making a choice, it is not so much a question of choosing the right as of the energy, the earnestness, the pathos with which one chooses." [15] Kierkegaard understands choice as intense thinking that coincides with the existence of the one who thinks. When one chooses with the whole weight of existence it is not the content that is important but the act of choosing itself. In choosing and standing up for one's choice the subject becomes a subject in the first place. The act of decision constitutes the subject as an autonomous entity in the point of maximal intensity.

This subject stands in opposition to the self that constructs itself as negation of negation, after it first created the other. Thus, the self is just the result of dialectical development. The primacy of the self, therefore, is nothing but a phantasy, just like the omnipotence of the subject that constitutes the world a priori. On the contrary, the self is not there before the other is created. Only through the separation from the other is the self constituted. Thus, the self emerges through its own positing. Paradoxically, the self sets itself as positioned. Therefore, it displays a negative identity. It is the result of the negation of negation and thus a heteronomous category.

The notion of intensity means that the absolute exists only as existential contingency. Therefore, there is no eternal truth but only concrete and singular truths. The paradox of absolute truth or universal law as singularity becomes manifest in Kafka's "Before the Law (Vor dem Gesetz)." Before the law, the simple country man realizes that there is no universal truth but only a truth just for him as a single person. This finding does not claim the relativity of truth, rather, that the truth is already singular, i.e., as a singular it is universal. Truth is not something that lies behind appearance, but something that arises with it, i.e., something that is deeply connected with appearance. The secret of absolute truth lies in the insight that it is its own appearance and that it coincides with the irreducible moment of absolute singularity. Thus, singularity becomes the indicator of truth.

Intensity is neither a part of the object nor a subjective category, even if it deals with emotions, perception, and sensual experience from time to time. It is neither objective nor subjective, but rather an event in which objective elements are indistinguishably intermingled with subjective ones: It is a state of indecisiveness and neutrality. It is a preindividual experience of the manifold that is constituted into a coherent whole only through the act of decision.

Intensity concerns the dimension before the formation of identity and thus functions as a categorical rejection of ontological identity. If there is no identity and instead only intensities, then diverse connections and new inventions are possible. Consequently, intensity evolves into a figure of future politics. Egregious and strange connections emerge from a decision as an act of sense-generating, at which the content of the decision does not play a significant role; instead the emphasis lies on the act of decision. In the intense act of decision, the content and the form of the decision coincide. In the moment of decision, existence is filled with maximal intensity until it opens up to the appearance of the transcendental and transitions completely into manifestation.

\section{Manifestation}

The question now is: How can the absolute exterior correlate with the absolute interior? How is it possible to think the relationship between the absolute exterior and the immanent point of decision? This is possible because the absolute exterior always manifests itself as immanent intensity. It is the irruption of the outer into the order of the topological space. The exterior is not just a spatial denotation: It is the point and the moment, the nonmeasurable, the unrepresentable parameter that alone marks the highest degree of intensity. It is the absolute difference, the difference in itself.

Whether this difference in itself is a place of absolute decision and differentiation or, rather, a place of undecidability and indistinguishability that constantly shifts - i.e., an instance of impossibility of a final decisiondepends on the framework of perspective. The framework of perspective is that which the subject has to construct first, because the framework of perspective or viewpoint is never neutral. It is inseparably connected with one's decision for a certain form of existence. It is a matter of an ethical decision for a particular way of life that is superior to an aesthetic modus of being. This ethical decision lets the "subject as ..." appear in the first place. Without this decision, there is no subject that already constitutes itself "as..." and gets manifest as such. The subject is always a manifestation in a particular way. It is the "manifestation as ...".

"Manifestation as ..." means that it is always a concrete and singular appearance that was yet undetermined before the moment of manifestation. The manifestation is the occurrence of an existence: In it, being occurs as a singularity. Only through manifestation does the anonymous mass get a name. Manifestation constitutes the "subject as ..." by virtue of granting a name, for being a subject is nothing other than the decision for a name.

Manifestation can't be separated from the notion of expression. Expression can be interpreted in two opposing ways: On the one the hand, expression stands for the notion of immanent causality. The absolute expresses itself in the modus of singularity because the absolute and the world share the same essence. In other words, the expression comes into being because the cause of the effect, the absolute, is inherent in the world. In his philosophy, Spinoza expresses this notion in a clear and prominent way. In the modern era, Deleuze, Foucault, and Rancière follow this thought. On the other hand, the expression stands for the irruption of the absolute into the world. It stands behind the notion of the 
transcendental. Therefore, the absolute has to fall into time to unfold itself. God has to create the world to actualize himself. This thought roots back to Schelling and, in modern times, finds prominent supporters like Heidegger, Lacan, Badiou, and Žižek. [16] But also in this thought of the transcendental, immanence is still of utmost importance because the absolute appears only immanently.

In the notion of expression, not only do the absolute and the world coincide but also the expressed and the expression. Thus, the expression is immanent to the expressed, that is, the expression and the expressed are one and the same. Expression is not a category in which the envelope and the enveloped could be distinguished from one another. Rather, the enveloped is the envelope itself. The expression doesn't express something that lies hidden behind the expression. It's an expression that, eventually, expresses nothing else but itself as pure manifestation. The expression as mere envelope, as shell coincides with the "expressionless." [17]

Manifestation is the occurrence of a singular ek-sistence. It is the simultaneity of the manifold that, in the critical "now time," reaches legibility and becomes the threshold between event and form. Thus, the notion of manifestation is a matter of the category of immanence. Manifestation is the material space for the effects of meaning and subjectification. However, it doesn't show the mysterious substance behind the visible façade; rather, the expression is already the substance. It's not about the expression of something but about the expression as the immediate manifestation or as the pure mediacy.

Manifestation belongs to the sphere of existence, not to the one of being. It is the complete affirmation of existence and being there. "The appearing being there exists." [18] Any system is superseded by life as the "unfolding of appearance." [19] Life is the opposite of a system. It is the non-system par excellence. According to Deleuze, life is not an organic system but an assemblage of intensities. Intensities encompass emotions, perceptions, and experiences. They enable the exchange between the interior and the exterior: they are contact zones. And life is nothing but a constant exchange and transition.

The status of the appearing existence is the Being-out-ofoneself. Thus, manifestation is always already outside: Manifestation ek-sists. But it is its own outer in the modus of expropriation and de-identification. Therefore, we always encounter manifestation outside where we are no longer by ourselves. As the non-self, we encounter manifestation. Hence, manifestation is not a visible object that lies outside of us. It is visible only in presenting itself as pure outer/outside. In this absolute outside where one can find manifestation, there is no longer a distinction between the image and the observer. Rather, both present themselves in one single setting, in which observer and picture become indistinguishable, or even in which the observer has become part of the picture. This is the ideal of the picture, which has to be understood not in the sense of a visible object but in the sense of an all-encompassing scenery. Hence, in manifestation there is no distinction between subject and object. There is no subject that observes and intervenes, and in the same way there is no object that has to be observed. Nonetheless, manifestation is the source for the new subjectivity. This new subjectivity is not an agent but the medium of occurrence itself. Thus, it is passive and active, susceptible and constructive, at the same time.

According to Benjamin, manifestation is a "pure means." [20] It is some kind of existence that manages without purpose or intention. It is the "performance of a mediacy," the "visualization of a means as such." [21] Although Benjamin tries to avoid the usage of purpose (for the purpose of ...) to emphasize the mediacy without purpose, the Kantian phrase "expediency without purpose" echoes in the notion of pure means. The point in the notion of manifestation is to stay in its own mediacy without any transcendence. Manifestation shows only pure mediacy: It is the disclosure or communication of mediacy. It opens up the space of politics precisely in this sense.

The notion of pure mediacy dispenses the distinction between end and means. It disables the end-means-relation in the first place, because from the start it is impossible to know the higher end. Hence, the notion of end in itself or of pure means would be nothing but a pretension. The notion of means that is subordinated to an end is also problematic, because the end cannot justify any means and needs another instance of authority for the evaluation of the appropriate means.

The order of manifestation is opposed to the order of means in the same way that the immediacy of mediation, i.e., the leap, is opposed to suspension. The dispute between the order of means and the order of manifestation is the same as the one between sign and image. The manifestation implies a critique of the referential order of signs because the sign is something superficial in regard to the signified, hence, there is no relation between them. Manifestation as image, however, is unintermediately the expression and the expressed itself.

In manifestation, future and present, remoteness and vicinity, converge. "The whole future is the brief present." [22] Future always takes place in the present time of now rather than as the present of the future. Subsequently, there is only a minimal difference between the present and the future, because the future only appears as split of the present. In the notion of manifestation, we find the pure immanence of the moment and not the revelation of the divine or, respectively, of the transcendent sense. One has to avoid the notion of epiphany here because it denotes the appearance of God according to Judeo-Christian tradition. Unlike the divine appearance as an epiphany, manifestation is without substance or reference. Manifestation is taken up in appearance itself. It is not the manifestation of something but rather manifestation as such, the pure expression that expresses nothing but its own appearance.

Consequently, manifestation is a matter of politics. Politics shows itself as a matter of the "spectacle," [23] of visibility and demonstration, of "allocation of the sensible" [24] on the social surface. Opponents of the spectacle, on the other hand, 
mobilize their own visibility and dispersion of the sensible. Subsequently, the political fight is more and more decided on the stage of politics. Politics is the fight over manifestation, a matter of the staging performance. Benjamin once put it appropriately: "History wanders on to the stage." [25]

The notion of manifestation always implies a space of visibility. This space, however, is split in two by the point of intensity, insofar as the point marks the place of differentiation. It is the instance of decision from where opposition is framed and endowed with value judgements. The point differentiates, for example, mind from matter, culture from nature, intellect from sensibility, masculinity from femininity, etc., whereby the first in each pair is endowed with a positive connotation (more developed, reasonable, active, etc.) and the second in each pair with a negative one (less developed, unreasonable, passive, etc.). Thus, it constitutes a topological space with a dualistic character. Where decisions are made, a topological space arises. The decision determines the topology of manifestation. It is necessary but contingent in the way of its topology.

The significance of manifestation for politics lies in the point that the new arising collective always manifests itself in the space of images. Manifestation is the modality of existence of the collective. ${ }^{1}$ Outside of manifestation-this visible configuration that fabricates a combination, a constellation out of the most heterogeneous elements - there is no collective, because the collective is that which becomes manifest and which turns manifestation into the proper place of politics.

Manifestation in itself, however, is a neutral notion. The immediacy of manifestation is not evidence for democracy, because it can turn into democracy as well as into dictatorship. Badiou already emphasized this ambivalence of the immediate manifestation of the collective. On a phenomenal level, one can't distinguish between the positing of a dictatorial power [26] and the immediate appearance of the people's will, because both of them are "an act of immediate manifestation of force." [27] This is the reason why Benjamin introduces the notion of "pure force," which supposedly distinguishes the force from its end-meansrelation forever. Hence, the "mythic force" is immediate but

1 In the following, the collective subject will be, according to Benjamin, who speaks of the collective body as well as of the collective. The concept of collective denotes organized as well as unorganized social constructs. A wellknown example of an organized political collective is the Marxist-communist collective. Benjamin's notion of the collective is influenced by Marxism, too, but differs from it. Since, for Benjamin, what is constitutive for a collective is not its class but its collective body. In contrast to population, masses, and people, the collective emphasizes the phenomenality, i.e., the appearance of the collective body as such. The collective is less organized than social groups that are subjected under a common goal and whose members interact with each other but in the moment of its manifestation appears as a community that is solely defined through joint action and common appearance. In other words: The act of manifestation constitutes the collective. In contrast to the Marxist concept of the collective, the collective of this study is distinguished by an openness and substancelessness. The collective in the moment of its manifestation is still amorphous and indefinable. It is not a denotation of a class or other substantive attributes. It is substanceless and thus can still become anything. not pure, because it arises from an interest in power. The "divine force" in contrast is pure and detached from all interest in power.

\section{Performance}

What post-structuralism has left is an empty place that stands for the contingency and inconsistency of a system. Theorists of the real refill this empty place with desubstantialized objects. Their method to fill this empty place is performance. Performance as an act of empowerment takes place at this empty place.

The discourse of the real places the origin of meaning and of the subject in the framework of manifestation as immediate self-presenting of the transcendental. In the act of manifestation, the subject grounds itself in the power it has set. The concurrence of image, subject, and force takes place in the modus of performance. Subsequently, the real is directly connected with the performance: Performance is the act of appointment of the real. The central point in performance one must emphasize here is that performance lets intensity emerge and become manifest. Without the performance of the act, the subject stays purely virtual. Its virtuality turns, thanks to performance, into actuality and becomes manifest corporeally.

Performance works as the conceptual instrument that makes the gap between sign and reference visible. Only after a performance is forgotten and pushed aside does reference appears instead. Reference is the procedure that lets the world appear as solid and necessary. Performance, on the other hand, makes the gaps in the world visible. The notions of performance and reference introduce two different ontological conceptions: On the one hand, world as incomplete and non-whole, on the other hand, world as completed and whole, infinitude or openness opposed to totality. [28] Performance is an action concept and, as such, opposed to the static, enclosed world-model from the start. Hence, the world appears as the place for restructuring and reshaping. Here we find the meaning of performance for the politics of the real.

The growth of performance goes along with the crises of representation. The more a reference of representation becomes insecure, the more performance comes to the fore. In this respect, the increasing medialization of the entirety of all aspects of human life in our society plays an eminent role for building theories of performance. On the one hand, medialization transforms the life-world into a virtual world and thus causes reference or reality to disappear. Subsequently, reality is superseded by hyperreality. On the other hand, medialization sharpens the gaze for materiality and the processuality of the medial process, which precedes the form of the life-world. Materiality and the processuality of the medial process, which influence the end product - the final form-significantly, become increasingly essential. The existing world turns into a becoming world. That which seems complete is exposed as incomplete. The solid forms turn out to be processes of becoming that are principally 
subjected to the contingency of the occurrence.

Performance renders reference-and thus the classical notion of mimesis-obsolete. It is not just a notion of philosophy of language or aesthetics but a radical critique of metaphysics. Metaphysics correlates with mimesis, whereas the theory of the real correlates with performance. In the conception of performance, the difference between original and copy disappears - a distinction that is indispensable for the concept of mimesis. According to Deleuze, performance is a "phantasm," [29] because it undermines the distinction between original and copy and instead affirms the permanent generating of new relations and nexuses. Hence, performance is the generation of freedom. But, performance is obliged to reality insofar as it always appears as a real act with real effects. Thus, it is also the real in Lacan's understanding. In short: It is the point of intersection between the Deleuzian immanence-philosophy and Lacan's transcendental philosophy. [30]

Performance acts as a disappearing intermediary between virtual intensity and actual manifestation. It is an antimetaphysical concept of possibility that differs strictly from metaphysical possibility. It doesn't act as the principle of form that dominates over matter. It doesn't presuppose any transcendence. It is a notion of immanence that nevertheless inscribes retroactively the place of the transcendental within immanence. Its function is solely to transform the virtual into the actual and the infinite into a concrete situation. [31]

\section{Conclusion}

The politics of the real makes the incompleteness of reality visible. Since reality is incomplete and imperfect it has to be restored through visualization of the hidden forces. This visualization happens in the process of performance. With the aid of performance, the politics of the real points out the necessity of transformation.

Intensity, manifestation, and performance correspond each to the virtual, actual, and possible of the real and thus are to be denoted as modalities of the politics of the real. In accordance with Deleuze, this study proceeds from the distinction between the virtual and the actual. The actual is not the realization of underlying possibilities but takes place as an actualization of the virtual, which constitutes itself subsequently in the moment of performance. In contrast to Deleuze, however, this study makes use of the third notion of the possible. The possible acts as the disappearing intermediary between the virtual and the actual. It is not to be considered as the ideal condition of possibility but as the real condition of reality of the actual. It is the performance that, in the moment of actualization, relates to the virtual retroactively.

The virtual is the transcendental condition of the infinite production of actuality, which, however, is strictly immanent. It is the transcendence of immanence. It correlates with the infinite which crystallizes as a constellation in the moment of actualization. It acts as the principle of transformation. The possible, on the other hand, is the reality-condition of the finite production of reality. It acts as the principle of continuity. The actual is not just connected to the virtual but also needs the possible, which performatively accomplishes the transition from the virtual to the actual. Not all of what is virtual will become actual. That which is actualized will thus have been virtual and possible at the same time whereas that which is not actualized stays solely virtual. The possible doesn't belong to the logical past but always to the future, because it arises from the seemingly impossible and it shows itself belatedly as that which has been possible all along. Before the effective actualization, everything is virtual. In the moment of actualization, the possible separates from the virtual and appears as such. The possible is always the refutation of the impossible. There, where one sees only the impossible, the possible suddenly takes place as the transition from the virtual to the actual. Transcendental idealism presupposes possibility as the transcendental condition of reality. Transcendental materialism, on the other hand, presupposes the possible as reality-condition of the actual and affirms the real as "historical a priori" in Foucault's sense. Thus, the politics of the real can be regarded as transcendental materialism. ${ }^{2}$

\section{References}

[1] Walter Benjamin, Gesammelte Schriften (= GS), Frankfurt a.M.: Suhrkamp 1980, II, p. 204.

[2] Walter Benjamin, GS, I, p. 1232.

[3] The most famous thinker of intensity is probably Deleuze. He denotes intensity as "pure difference in itself": "[N]ot qualitative opposition within the sensible, but an element which is in itself difference, and creates at once both the quality in the sensible and the transcendent exercise within sensibility. This element is intensity, understood as pure difference in itself, as that which is at once both imperceptible for empirical sensibility which grasps intensity only already covered or mediated by the quality to which it gives rise, and at the same time that which can be perceived only from the point of view of a transcendental sensibility which apprehends it immediately in the encounter." Gilles Deleuze, Difference and Repetition, New York: Columbia University Press 1994, p. 144.

[4] For the notion of "point" see Badiou's theory of points: Alain Badiou, Logics of Worlds, New York: Continuum 2009, p. 399-435. Here, Badiou combines the notion of the point with the notion of decision. "A point of the world (in effect, of the transcendental of a world) is that which makes appear the infinity of the nuances of a world - the variety of the degrees of intensity of appearing, the branching network of identities and differences - before that instance of the Two which is the 'yes' or 'no', affirmation or negation, surrender or refusal, commitment or indifference... In brief, a point is the crystallization of the infinite in the figure-which Kierkegaard called 'the Alternative' - of the 'either/or', what can also be called a choice or a decision.” Ibid., p. 399-400.

[5] Roland Barthes, Das Neutrum, Frankfurt a.M.: Suhrkamp 2005 , p. 322.

2 This paper is translated from German to English by Heidi Samuelson and Stefan W. Schmidt. 
[6] Roland Barthes, Das Neutrum, Frankfurt a.M.: Suhrkamp 2005 , p. 324.

[7] Walter Benjamin, GS, II, p. 203.

[8] See Karl Heinz Bohrer, Ekstasen der Zeit. Augenblick, Gegenwart, Erinnerung. München: Hanser 2003, p. 72.

[9] Karl Heinz Bohrer, Ekstasen der Zeit. Augenblick, Gegenwart, Erinnerung. München: Hanser 2003, p. 72.

[10] See Carl Schmitt, Politische Romantik, Berlin: Duncker \& Humblot 1998, p. 62-113.

[11] See Karl Heinz Bohrer, Ekstasen der Zeit. Augenblick, Gegenwart, Erinnerung. München: Hanser 2003, p. 79.

[12] See Gilles Deleuze, The Logic of Sense, London: The Athlone Press 1990, p. 66-73.

[13] Badiou gives Kierkegaard credit for the discovery that "the theory of the point is a formal or transcendental theory." See Alain Badiou, Logics of Worlds, New York: Continuum 2009, p. 432. In Kierkegaard's vocabulary, it means that "the essence of choice is choice itself, not what is chosen". Ibid., p. 433.

[14] "Hegel tells us that since God appeared in historical time, it is necessary to know the stages of the becoming-subject of the Absolute. Kierkegaard replies that for precisely the same reason, knowing is useless. It is necessary to experience the Absolute as subjective inwardness. That is why, for Kierkegaard, there cannot exist a moment of knowledge ('absolute knowledge', in Hegel's terms) where truth is complete or present as a result. Everything commences, or recommences, with each subjective singularity." Alain Badiou, Logics of Worlds, New York: Continuum 2009, p. 426-427. According to Badiou, Kierkegaard argues that "thought and truth must not simply account for their being, but also for their appearing, which is to say for their existence. That the Christ came is the emblem of this demand." Ibid., p. 427.

[15] Alain Badiou, Logics of Worlds, New York: Continuum 2009, p. 432.

[16] Both notions of expression - as immanent causality and as transcendental-basically stand as a decision between materialism and idealism. In Deleuze's philosophy of immanence, for example, expression is replaced by production. Expression, therefore, is such a production wherein the producer is immanent to the produced. See Gilles Deleuze and Félix Guattari, Anti-Oedipus. Capitalism and Schizophrenia, Minneapolis: University of Minnesota Press 1983.

[17] Based on this account Benjamin constructs his concept of the expressionless as appearance of the sublime. See Walter Benjamin, "Goethes Wahlverwandtschaftten", in: Walter Bejamin, GS, I, p. 123-201.

[18] See Jean Grenier, L'Esprit du Tao, Paris: Flammarion 1972, p. 15.

[19] See Roland Barthes, Das Neutrum, Frankfurt a. M.: Suhrkamp 2005, p. 283.

[20] Walter Benjamin, GS, II, p. 184.

[21] See Giorgio Agamben, Mittel ohne Zweck. Notizen zur Politik, Zürich/Berlin: Diaphanes 2006, p. 54.

[22] See Karl Heinz Bohrer, Ekstasen der Zeit. Augenblick, Gegenwart, Erinnerung, München: Hanser 2003, p. 65.
[23] See Guy Debord, The Society of the Spectacle, New York: Zone Books 1995.

[24] See Jacques Rancière, Disagreement: Politics and Philosophy, Minneapolis: University of Minnesota Press 1998.

[25] Walter Benjamin, GS, I, p. 271.

[26] According to Schmitt each grounding power is dictatorial, although he distinguishes between a constitutional sovereign and an unconstitutional commissarial dictatorship. See Karl Schmitt, Die Diktatur. Von den Anfängen des modernen Souveränitätsgedankens bis zum proletarischen Klassenkamp, Berlin: Duncker \& Humblot 1994.

[27] Walter Benjamin, GS, II, p. 198.

[28] Jürgen Villers points out correctly that the referential and performative accounts of language are based on totally different ontological conceptions: „Gegenüber der referentiellen Bedeutung kann man in der Sprache so von einem Überschuss an Sinn sprechen, wenn man verstanden hat, dass der Prozess der sprachlichen Ausdifferenzierung von Sinn aufgrund der angesprochenen unendlichen Menge der Oppositionen ein prinzipiell unbegrenzter ist. So wie die gegenstandstheoretische Repräsentationskonzeption eine statische Ordnung der Ontologie impliziert, korreliert der sprachphilosophischen Handlungstheorie der Bedeutung, die den performativen Charakter sprachlicher Medialität anerkennt, ein dynamisch-konstruktives Wirklichkeitsverständnis". ["In contrast to the referential meaning, we can speak of a surplus of sense in language, if one has understood that the process of linguistic differentiation of sense is in principle infinite because of the mentioned infinite multitude of oppositions. Just as the subject-theoretical conception of representation implies a static order of ontology so the linguistic-philosophical action theory of meaning which acknowledges the performative character of linguistic mediality correlates with a dynamic-constructive understanding of reality."] Jürgen Villers, Die performative Wende. Austins Philosophie sprachlicher Medialität, Würzburg: Königshausen \& Neumann 2011, p. 20.

[29] See Gilles Deleuze, The Logic of Sense, London: The Athlone Press 1990, p. 253-266.

[30] Deleuze himself tries to close the gap between a philosophy of immanence and transcendental philosophy by introducing the notion of the "transcendental field" into his philosophy and denotes this as "a pure plane of immanence." See Gilles Deleuze, "Immanence: A Life", in: Gilles Deleuze, Pure Immanence: Essays on A Life, Cambridge, Massachusetts/London: The MIT Press 2005, p. 31.

[31] Deleuze writes in his essay "Immanence: A Life": "What we call virtual is not something that lacks reality but something that is engaged in a process of actualization following the plane that gives it its particular reality. The immanent event is actualized in a state of things and of the lived that make it happen. The plane of immanence is itself actualized in an object and a subject to which it attributes itself. But however inseparable an object and a subject may be from their actualization, the plane of immanence is itself virtual, so long as the events that populate it are virtualities. [...] There is a big difference between the virtuals that define the immanence of the transcendental field and the possible forms that actualize them and transform them into something transcendent." Gilles Deleuze, "Immanence: A Life", in: Gilles Deleuze, Pure Immanence: Essays on A Life, Cambridge, Massachusetts/London: The MIT Press 2005, p. 31-32. 